\title{
Hemolysis Combined with Renal Injury after Mitral Valve Repair
}

\author{
Xian Zhu, MD, ${ }^{1}$ Zhanglong Hu, MD, ${ }^{1}$ Lili Fang, MD,${ }^{2}$ Jie Li, MD,${ }^{3}$ Haifeng Cheng, MD,${ }^{1}$ \\ Daming Jiang, $\mathrm{MD}^{1}$ \\ ${ }^{1}$ Department of Cardiovascular Surgery and ${ }^{2}$ Department of Anesthesiology, 2nd Affiliated Hospital, School of Medicine, \\ Zhejiang University, Hangzhou, China; ${ }^{3}$ Guangdong Cardiovascular Institute, Guangdong General Hospital, Guangdong \\ Academy of Medical Science, Guangzhou, China
}

\section{ABSTRACT}

Hemolysis combined with renal injury is a rare but serious complication after mitral valve repair. Here, we report two representative cases of hemolysis combined with renal injury. Although timely reoperation was not possible for several reasons, different clinical outcomes were observed that could aid in future decisions.

\section{INTRODUCTION}

Hemolytic anemia after mitral valve repair is a rare and serious complication of mitral regurgitation (MR); it can induce acute kidney injury, and even cause irreversible damage. Thereby, we report two representative cases related to hemolysis combined with renal injury after mitral valve repair, and discuss the mechanisms and treatment experience.

\section{CASE REPORT}

\section{Case 1}

Upon echocardiography, a 67-year-old woman with dyspnea on exertion was found to have severe MR with a prolapsed P1 segment, and severe tricuspid valve regurgitation (Figure 1A). The patient underwent mitral valve repair, and tricuspid valve repair. The mitral valve repair procedure consisted of a rectangular resection of the $1 \mathrm{~cm}$ wide $\mathrm{P} 1$ section, and annuloplasty with a $28 \mathrm{~mm}$ prosthetic annuloplasty ring (Edwards). Intraoperative transesophageal echocardiography (TEE) showed no significant mitral regurgitation jet after valve repair. Ten days after the surgery, repeated echocardiography showed mild residual mitral regurgitation (Figure 1B). The postoperative course was uneventful and the patient was discharged.

Two months later, the patient came back with shortness of breath and palpitations. Hematology examination showed that hemoglobin was $7 \mathrm{~g} / \mathrm{dL}$, indirect bilirubin was 28.4 umol/l, total bilirubin was $35.2 \mathrm{umol} / \mathrm{L}$, lactate dehydrogenase $(\mathrm{LDH})$ was $2218 \mathrm{u} / \mathrm{L}$, haptoglobin $<0.06 \mathrm{~g} / \mathrm{L}$, ferritin was

Received October 24, 2017; received in revised form February 27, 2017; accepted April 27, 2018.

Correspondence: Dr. Fiang, Department of Cardiovascular Surgery, 2nd Affiliated Hospital, School of Medicine, Zhejiang University, 88 FieFang Road, Hangzhou, P.R.China, 310009; (e-mail: to_jiangdm@zju.edu.cn).
$318.80 \mathrm{ng} / \mathrm{mL}$. Renal function is normal. A peripheral blood smear indicated the intravascular hemolysis with schistocytes (Figure 2A). After the transfusion of three units of red cell, the level of hemoglobin increased to over $8 \mathrm{~g} / \mathrm{dL}$ and was kept stable for two weeks, and the patient was discharged.

Only one week later, the patient was admitted again for severe vomiting and diarrhea. Hematology examination showed significant acute kidney injury: blood urea nitrogen (BUN) was $23.95 \mathrm{mmol} / \mathrm{L}$ and creatinine was $197.14 \mu \mathrm{mol} / \mathrm{L}$. Urinary hemosiderin determination was positive. Then, a sudden cerebral infarction was found in the patient, with the symptoms of left limb muscle weakness and twisted mouth. Because of the unexpected event, reoperation was not performed. Fortunately, after transfusion and medical therapy of adalat gits and $\beta$-blocker, hemolysis anemia was improved significantly. Hemoglobin increased to $9.2 \mathrm{~g} / \mathrm{dL}$ at the time when the patient was discharged one month later. Hemolytic anemia disappeared rapidly during the subsequent follow-up, and renal function was recovered to normal.

\section{Case 2}

A 68-year-old woman was admitted to the hospital for recurrent chest distress. Echocardiography revealed severe mitral valve regurgitation, with prolapse of segments $\mathrm{A} 2$ and A3 (Figure 1C). Preoperative renal function was normal. The patient underwent mitral valve repair with a $26 \mathrm{~mm}$ annuloplasty ring (Edwards), and new chordae implantation for the prolapsed anterior leaflet. Intraoperative TEE showed mild residual mitral regurgitation. Postoperative macroscopic hematuria was observed. Hematology examination showed that hemoglobin was $7.3 \mathrm{~g} / \mathrm{dL}$, indirect bilirubin was $37.2 \mathrm{umol} / \mathrm{L}$, total bilirubin was $60.8 \mathrm{umol} / \mathrm{L}$, LDH was $1483 \mathrm{u} / \mathrm{L}$, haptoglobin $<0.06 \mathrm{~g} / \mathrm{L}$, ferritin was $859.6 \mathrm{ng} / \mathrm{mL}$, creatinine was $184 \mu \mathrm{mol} / \mathrm{L}$ and BUN was $16.07 \mathrm{mmol} / \mathrm{L}$. Comb's test was negative. A peripheral blood smear indicated intravascular hemolysis with schistocytes (Figure 2B). The patient was treated with blood transfusion, alkalization of urine, and medication. The postoperative echocardiography showed mild regurgitation of the mitral valve (Figure 1D). Before discharged, hemoglobin was $8.1 \mathrm{~g} / \mathrm{dL}$ and the renal function restored to normal.

Three months later, the patient was readmitted for serious recurrent anemia and impaired renal function. Because of personal reasons, the patient refused reoperation all the time. One year later, the patient was admitted with recurrent 

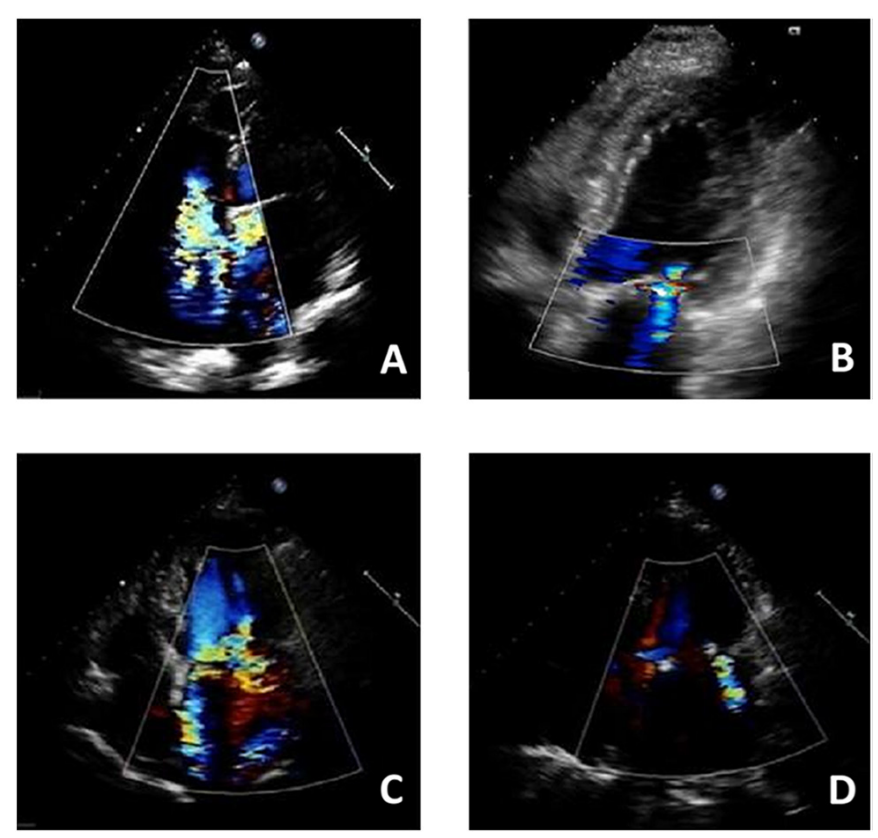

Figure 1. (A) Preoperative echocardiogram of the case 1, showing severe regurgitation of MV (mitral valve). (B) Postoperative echocardiogram of the case 1, showing mild regurgitation of MV. (C) Preoperative echocardiogram of the case 2, showing severe regurgitation of MV. (D) Postoperative echocardiogram of the case2, showing mild regurgitation of MV.

hemolysis once again, and renal dynamic imaging showed severe renal dysfunction. The patient then underwent mitral valve replacement with a bioprosthesis. During follow-up, although hemolytic anemia resolved, renal function did not restore.

\section{DISCUSSION}

The previous data show that hemolysis after mitral valve repair can be classified into three categories: collision of regurgitation jet to the prosthetic ring, rapid acceleration regurgitation jet, and fragmentation jet caused by the dehisced prosthetic ring [Viaene 2013]. High shear stress contributes significantly to the pathophysiology of hemolysis that is demonstrated by TEE [Yeo 1998]. Furthermore, other occurrences were considered to be related to hemolysis, such as the failure of the repair, progression of the valve disease, prosthetic annuloplasty rings, disrupted sutures or pledgets, etc.

Compared to isolated hemolysis, hemolysis combined with kidney injury is rarer. Only a few cases have introduced personal experience of diagnosis and treatment. Moderate levels of hemoglobin do not damage the tissue [Schaer 2014]. However, when massive amounts of hemoglobin are released into the plasma so that haptoglobin is exhausted, the residual hemoglobin is incorporated by tubular cells and is then dissociated into free-heme and iron [Concepcion 2008; Rother 2005]. All the various pathological process could be summarized as follows:

1) Direct damage. The increased level of heme could induce oxidation, protein denaturation, and proinflammatory
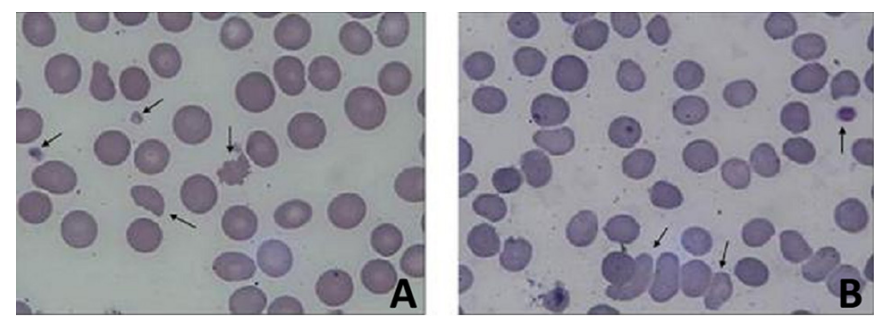

Figure 2. (A) Case 1: Peripheral blood smear showing abnormal red cell and fragmented red blood cells (black arrows). (B) Case 2: Peripheral blood smear showing abnormal red cell and fragmented red blood cells (black arrows).

and free radicals to cause cytotoxic effects and result in cell necrosis and apoptosis [Dutra 2014].

2) Cast formation. In an acidic environment, hemoglobin is rapidly converted to methemoglobin, which can form casts by precipitating within the distal tubular lamina. The obstruction increases proximal tubular hemoglobin uptake, causing lysosomal overload and further cell death [Khalighi 2015].

3) Vascular dysfunction. Excessive free plasma hemoglobin could react with nitric oxide (NO) rapidly and irreversibly, producing nitrate and methemoglobin. Serious depletion of NO could impair vascular function, elevate vascular resistance and decrease organ perfusion [Shih 2013].

Given the incomplete endothelialization of prosthetic material early after the operation, acute renal injury induced by hemolysis could be self-limited if timely and effective therapy is performed [Gungunes 2010]. Introducing medicine, slowing down the heart rate, and decreasing blood pressure could alleviate the hemolysis. Blood transfusion could be used for anemia. In addition, therapeutic plasma exchange, haptoglobin, and inhaled NO could possibly be useful as well [Hayes 2015; Shih 2013].

The decision of reoperation requires serious consideration, because the rate of mortality and complication is significantly higher in the second operation than in the first [Cardoso 2013]. The indications for the timing and approach of the reoperation need to be studied further. According to current views, conservative therapy, as outlined above, is always the first choice against the hemolysis. Conservative therapy could avoid the injury caused by reoperation, and the excessive hospital expense. However, the patients require more intense observation. If recurrent hemolysis and renal injury still exist after conservative treatment, and regurgitation jet with high shear stress is proved by TEE, reoperation should be conducted more positively. Otherwise, it will cause serious anemia and chronic irreversible renal injury.

Mitral valve repair and mitral valve replacement are both options for reoperation, as they both resolve the serious hemolysis successfully. The preferred option should be determined according to factors such as age, valve quality, and other individual characteristics of the patients [Abourjaili 2012].

In both of our two cases, the initial hemolysis occurred nearly two months after mitral valve repair. This is consistent with the data of the past study [Lam 2004]. Mild mitral valve regurgitation was observed in the two patients by echocardiography after surgery. The key point was that re-operation 
was not made for necessary reasons in the both patients when hemolysis combined with renal injury occurred. In the first case, hemolysis gradually disappeared and renal function restored to normal, which might contribute to the complete endothelialization of prosthetic material. In the second case, continuous hemolysis caused irreversible kidney injury, and it could not be improved by surgery or the removal of hemolysis.

In summary, strong attention should be paid to kidney dysfunction, since the recurrent hemolysis appears in accordance with the different outcomes of the two cases. Careful echocardiographic evaluation and timely laboratory examination could be conducive in allowing us to predict the development of the hemolysis. Once conservative therapy is actually ineffective, re-operation should be made as soon as possible.

\section{ACKNOWLEDGEMENT}

Support: the Medical Project of Zhejiang Province (2012KYB089).

\section{REFERENCES}

Abourjaili G, Torbey E, Alsaghir T, et al. 2012. Hemolytic anemia following mitral valve repair: A case presentation and literature review. Exp Clin Cardiol, 17:248-50.

Cardoso C, Cachado P, Garcia T. 2013. Hemolytic anemia after mitral valve repair: a case report. BMC Res Notes, 6:165

Concepcion B, Korbet SM, Schwartz MM. 2008. Intravascular hemolysis and acute renal failure after mitral and aortic valve repair. Am J Kidney Dis $52: 1010-5$.
Dutra FF, Alves LS, Rodrigues D, et al. 2014. Hemolysis-induced lethality involves inflammasome activation by heme. Proc Natl Acad Sci USA 111:E4110-8.

Gungunes A, Akpinar I, Dogan M, et al. 2010. Do all hemolytic anemias that occur after mitral valve repair require surgical treatment? Clin Cardiol 33:E76-8.

Hayes C, Shafi H, Mason H, et al. 2015. Successful reduction of plasma free-hemoglobin using therapeutic plasma exchange: A case report. Transfus Apher Sci 54: 253-5.

Khalighi MA, Henriksen KJ, Chang A, et al. 2015. Intratubular hemoglobin casts in hemolysis-associated acute kidney injury. Am J Kidney Dis 65:337-41.

Lam BK, Cosgrove DM, Bhudia SK, et al. 2004. Hemolysis after mitral valve repair: mechanisms and treatment. Ann Thorac Surg 77:191-5.

Rother RP, Bell L, Hillmen P, et al. 2005. The clinical sequelae of intravascular hemolysis and extracellular plasma hemoglobin: a novel mechanism of human disease. JAMA 293:1653-62.

Schaer DJ, Vinchi F, Ingoglia G, et al. 2014. Haptoglobin, hemopexin, and related defense pathways-basic science, clinical perspectives, and drug development. Front Physiol 5:415.

Shih HM, Chen YC, Pan CF, et al. 2013. Hemolysis-induced acute kidney injury following cardiac surgery: a case report and review of the literature. Hemodial Int 17:101-6.

Viaene E, Schroeyers P, Dujardin K. 2013. Haemolysis and acute renal failure after mitral valve repair. Acta Cardiol 68:189-91.

Yeo TC, Freeman WK, Schaff HV, et al. 1998. Mechanisms of hemolysis after mitral valve repair: assessment by serial echocardiography. J Am Coll Cardiol 32: 717-23. 